\title{
O ENSINO DE BIOSSEGURANÇA EM CURSOS TÉCNICOS EM ANÁLISES CLÍNICAS
}

\author{
THE TEACHING OF BIOSECURITY IN TECHNICAL COURSES ON CLINICAL ANALYSES
}

\author{
Andrezza Piccoli ${ }^{1}$ \\ Mônica Wermelinger ${ }^{2}$ \\ Antenor Amâncio Filho ${ }^{3}$
}

Resumo Há um descompasso entre as exigências do mercado de trabalho em saúde e o ensino médio técnico profissionalizante. A busca pela compreensão de um dos aspectos relativos ao distanciamento entre a formação profissional do técnico em análises clínicas e as necessidades do mundo do trabalho é enfocada nesta pesquisa. O trabalho tem como objetivo geral compreender a metodologia de ensino utilizada por docentes em biossegurança de escolas técnicas de formação em análises clínicas concomitante ao ensino médio da Região Metropolitana do Rio de Janeiro, tendo como campo para coleta de dados unidades de ensino da rede pública do Estado do Rio de Janeiro. Em se tratando de um estudo de caso com abordagem qualitativa, as informações foram obtidas através de entrevistas gravadas orientadas por questionário semiestruturado e analisados conteúdo e discurso de três docentes em biossegurança. Os resultados da pesquisa sugerem a necessidade de reformulações da prática pedagógica, possibilitando que a formação do técnico em análises clínicas ocorra de forma mais consoante às reais necessidades do mercado privado ou público representado pelo Sistema Único de Saúde.

Palavras-chave biossegurança; saúde coletiva; educação; formação profissional em saúde; análises clínicas.
Abstract There is a discrepancy between the demands of the labor market in the health sector and professional technical colleges. The quest for comprehension of one of the aspects pertaining to the distance between professional formation of technicians in clinical analyses and the necessities of the labor market is the focus of this research. The general purpose of this study is to understand the teaching methodology used by professors in biosecurity at technical colleges that offer courses in clinical analyses, in conjunction with a high school in the Metropolitan Region of Rio de Janeiro, where data was collected from Public Teaching Units of the State of Rio de Janeiro. When dealing with a case study with a qualitative approach, information was obtained by means of recorded interviews that were guided by a semi-structured questionnaire, whose content was analyzed by three biosecurity professors. The results of the survey indicate the necessity for reformulations in pedagogic practice, enabling the formation of technicians in clinical analyses to be more in line with the actual necessities of the private or public market represented by the Public Health System (SUS).

Keywords biosecurity; collective health; education; professional formation in health; clinical analyses. 


\section{Introdução}

A biossegurança, cada vez mais presente no cotidiano do profissional de saúde, designa um campo de conhecimento e um conjunto de práticas e ações técnicas, com preocupações sociais e ambientais, destinados a conhecer e controlar os riscos que o trabalho pode oferecer ao ambiente e à vida (Almeida e Albuquerque, 2000). Na saúde é possível observar um grande número de situações que apresentam riscos ocupacionais, ${ }^{4}$ mormente se considerado que o hospital é, de maneira geral, o principal ambiente de trabalho dos profissionais que atuam nessa área (Sousa, 1994). Esta é uma das razões que ressaltam a importância do ensino de biossegurança na formação profissional como orientador das práticas inerentes ao cotidiano do trabalho em saúde.

De acordo com Teixeira e Valle, a biossegurança é caracterizada como

O conjunto de ações voltadas para a prevenção, minimização ou eliminação de riscos inerentes às atividades de pesquisa, produção, ensino, desenvolvimento tecnológico e prestação de serviços, riscos que podem comprometer a saúde do homem, dos animais, do meio ambiente ou a qualidade dos trabalhos desenvolvidos (Teixeira e Valle, 1996, p. 13).

A biossegurança é, portanto, tema de extrema relevância no dia a dia dos profissionais de saúde e precisa estar presente ao longo do processo de aprendizagem dos alunos dos cursos de formação técnica em saúde para que, no futuro, saibam resguardar-se de riscos ocasionados por desconhecer a maneira adequada de proceder em dada situação. Atualmente, o mercado de trabalho tem buscado profissionais técnicos que estejam mais atualizados em relação às normas, aos regulamentos e à legislação vigente sobre como realizar determinados procedimentos, conhecimentos esses que os tornam mais aptos para prevenir e evitar erros, que às vezes podem ser fatais no exercício da profissão.

Com frequência, profissionais que atuam em unidades de saúde, seja por desconhecimento de medidas de segurança, seja por uma exagerada autoconfiança no que fazem, ignoram a necessidade de maiores cuidados na prática de determinados atos. Um dos motivos que levam a esse modo de pensar e de agir é decorrente da formação desses profissionais, marcada por um descompasso entre as áreas da educação e da saúde:

De um modo geral, a educação vem formando profissionais para atuar na saúde sem considerar as carências e necessidades do setor e este, por sua vez e também de modo geral, procura criar condições para suprir as deficiências técnicas dos profissionais que incorpora. (...) Esse panorama, no qual os denominados "aparelho 
formador" (educação) e "aparelho absorvedor" (saúde) desenvolvem ações desconexas, torna obrigatório, para os profissionais das duas áreas, refletir sobre propostas educacionais que almejem romper com uma situação historicamente falha (Amâncio Filho, 1997, p. 11).

Segundo Ribeiro, Ribeiro e Lima Júnior (2010), dentre as categorias profissionais da área da saúde, a mais exposta ao risco é a formada por técnicos e auxiliares de enfermagem, com um predomínio de 43,4\%. Entretanto, o técnico em análises clínicas é o mais exposto aos acidentes, visto que é o profissional que realiza procedimentos de coleta venosa para a realização de exames laboratoriais. Outros autores (Rapparini, 2001; Mastroeni, 2004) evidenciaram em suas pesquisas que os técnicos em análises clínicas estão mais sujeitos a casos de infecções causadas por procedimentos não condizentes com a boa prática laboratorial, como pipetar com a boca ou usar inadequadamente perfurocortantes.

Levantamento realizado pela Secretaria Municipal de Saúde do Rio de Janeiro de 1997 a 2005 (Rapparini, 2001) constatou que 15\% dos acidentes notificados eram referentes à coleta de sangue e punção venosa periférica, $14 \%$ ao recapeamento de agulhas, $13,6 \%$ a manuseio de material cirúrgico e cirurgias, $13,4 \%$ em descarte, $13,1 \%$ em manuseio de lixo e 7,4\% na administração de medicamentos. Estes dados demonstram a relação direta dos acidentes às atividades exercidas nas unidades de assistência à saúde com maiores fatores de risco. De acordo com Mastroeni (2004), os profissionais de saúde mais sujeitos a infecções ocupacionais são os da área de laboratório, entre os quais são diagnosticadas desde doenças fúngicas, como coccidioidomicose e dermatomicoses, até doenças mais graves, como tuberculose, hepatite B e Aids.

Além dos riscos presentes na rotina de trabalho dos profissionais da saúde, em especial na dos técnicos, a flexibilização do mercado de trabalho faz realçar a importância da formação. No contexto atual, o mercado mostra significativas transformações, em consequência de um processo de globalização, caracterizado por Giddens (apud Santos, 2005, p. 26) como “a intensificação de relações sociais mundiais que unem localidades distantes, de tal modo que os acontecimentos locais são condicionados por eventos que acontecem a muitas milhas de distância e vice-versa". Essa dinâmica global acarreta mudanças não apenas na natureza do próprio trabalho, mas também no tocante às relações político-econômicas e sociais, com efeito desestabilizador sobre direitos de cidadania conquistados ao longo do tempo, como o direito à saúde, à educação, ao emprego, à renda, ao lazer.

A influência dessas transformações no setor saúde pode ser mais bem notada e compreendida mediante a observação de dicotomias que sobressaem na realidade atual. Três exemplos: a) se antes a regra era incentivar um 
tipo de profissional passivo, obediente, disciplinado e altamente qualificado para desempenhar suas atividades, hoje o que se espera é que o profissional seja ativo, empreendedor e criativo, que tenha desenvolvido e domine competências para desempenhar suas funções; b) hoje, ao contrário de empregos estáveis, se estabelecem entre empregador e empregado contratos de prazo preestabelecido para a prestação de determinados serviços; c) o profissional com formação sólida mais específica é preterido por aquele com formação polivalente, mais facilmente adaptável à realidade do mercado e concebido como 'cidadão produtivo' em substituição ao antigo 'operário padrão':

O campo da qualificação, formação continuada e, mais amplamente, do educativo da escola básica à pós-graduação, no quadro do ajuste global, é direcionado para uma concepção produtivista, cujo papel é o de desenvolver habilidades de conhecimento, de valores e atitudes e de gestão da qualidade, definidas no mercado de trabalho e cujo objetivo é o de formar em cada indivíduo um banco ou reserva de competências que lhe assegure empregabilidade (Frigotto, 2011, p. 7).

Segundo Lessa (2008), a expansão do capitalismo fez com que a quantidade de bens produzidos se tornasse maior do que a demanda do consumo. Esse aumento da oferta de produtos resultou em preços insuficientes para cobrir todos os custos de produção. Para enfrentar esse déficit, promoveuse uma precarização das etapas do processo de produção, desde a obtenção de matéria-prima até a destinação de resíduos industriais.

Situação equivalente pode ser observada no mercado de trabalho de serviços, particularmente no segmento representado pela área de análises clínicas. A cada dia, um contingente de novos profissionais procura ingressar no mercado, resultado do aumento da oferta das unidades formadoras de recursos humanos, tanto no âmbito da educação formal (representada pelas escolas regulares, estaduais e federais) como no da saúde (podendo ser mencionada a Rede de Escolas Técnicas do SUS - RET-SUS). Com isso o mercado se torna saturado de profissionais legalmente aptos ao trabalho em laboratório clínico, o que ocasiona uma flexibilização cada vez maior de vínculos. Os empregadores oferecem valores de remuneração reduzidos e os profissionais, por sua vez, vendem sua força de trabalho abaixo do valor de mercado, fortalecendo um ciclo de degradação que tem como uma das suas consequências a perda de direitos trabalhistas e a desagregação de uma categoria representativa no mercado em saúde.

Por sua vez, Sader (2008) assinala que a força de trabalho se tornou uma mercadoria cada vez mais desvalorizada. O profissional vê-se constrangido a aceitar um salário proposto, pois se não o fizer haverá outro profissional disponível para ocupar o lugar que lhe está sendo oferecido, dentro das 
condições do empregador. Além de salários, os investimentos para que os laboratórios se mantenham atualizados em relação aos avanços tecnológicos, em termos de diagnóstico, implicam aumento nos custos. Como o empregador não tem condições, ou interesse em manter em nível elevado e equilibrado os aspectos tecnologia, salário, condições de trabalho e lucro, opta por precarizar as relações de trabalho e por relegar ao segundo plano as condições de trabalho. Com isso, proporciona-se um forte investimento em equipamentos de alta tecnologia para que possam ser feitas as análises, em detrimento das condições remuneratórias e de trabalho do profissional da saúde. Equipamentos de proteção individual ou coletiva, materiais descartáveis, vestimentas adequadas, cabines de segurança biológica ou capelas de segurança química, programas de capacitação profissional e de controle de qualidade intralaboratorial são medidas que, infelizmente, vêm escasseando no espaços/serviços da saúde.

O que se verifica são unidades sem as condições mínimas de segurança para o trabalho, escassez de insumos, espaços laboratoriais muitas vezes mal adaptados, falta de planejamento e de programas de atualização/capacitação profissional. Em relação, especificamente, aos técnicos em análises clínicas, essa situação pode ser observada nos laboratórios das unidades públicas que compõem o SUS, uma realidade que reflete as mudanças operadas nas relações público-privado, caracterizadas por Bahia (2008) e Pereira (2008).

Diante dos graves problemas assinalados, fica evidente a importância de empreender uma investigação sobre a educação profissional de nível médio em saúde no Brasil (Wermelinger, Machado e Amâncio Filho (2010). Como repensar os currículos e a estrutura dos cursos, tendo em vista a emancipação profissional? Em que contexto estes profissionais são inseridos? Como a prática docente pode influenciar as atividades futuras exercidas por estes profissionais? Tais questionamentos servem como pano de fundo para desvelar os meandros da formação e da atuação do técnico em análises clínicas no SUS, contribuindo para melhor compreender a importância de discutir e, talvez, reformular o processo de formação desse profissional.

\section{Formação profissional técnica em análises clínicas}

De acordo com as diretrizes curriculares nacionais para a educação profissional de nível técnico instituídas pela resolução n. 4, de 8 de dezembro de 1999, da Câmara de Educação Básica do Conselho Nacional de Educação, devem ser desenvolvidas competências profissionais gerais para a formação do técnico de nível médio da área da saúde (Brasil, 1999). No que tange à biossegurança e, em especial, no que diz respeito ao técnico em análises 
clínicas, é possível estabelecer uma relação das competências mais significativas com os conceitos que podem estimular o desenvolvimento delas, como se pode observar no Quadro 1.

\section{Quadro 1}

Competências do técnico de nível médio em saúde e perspectivas de trabalho no ensino de biossegurança

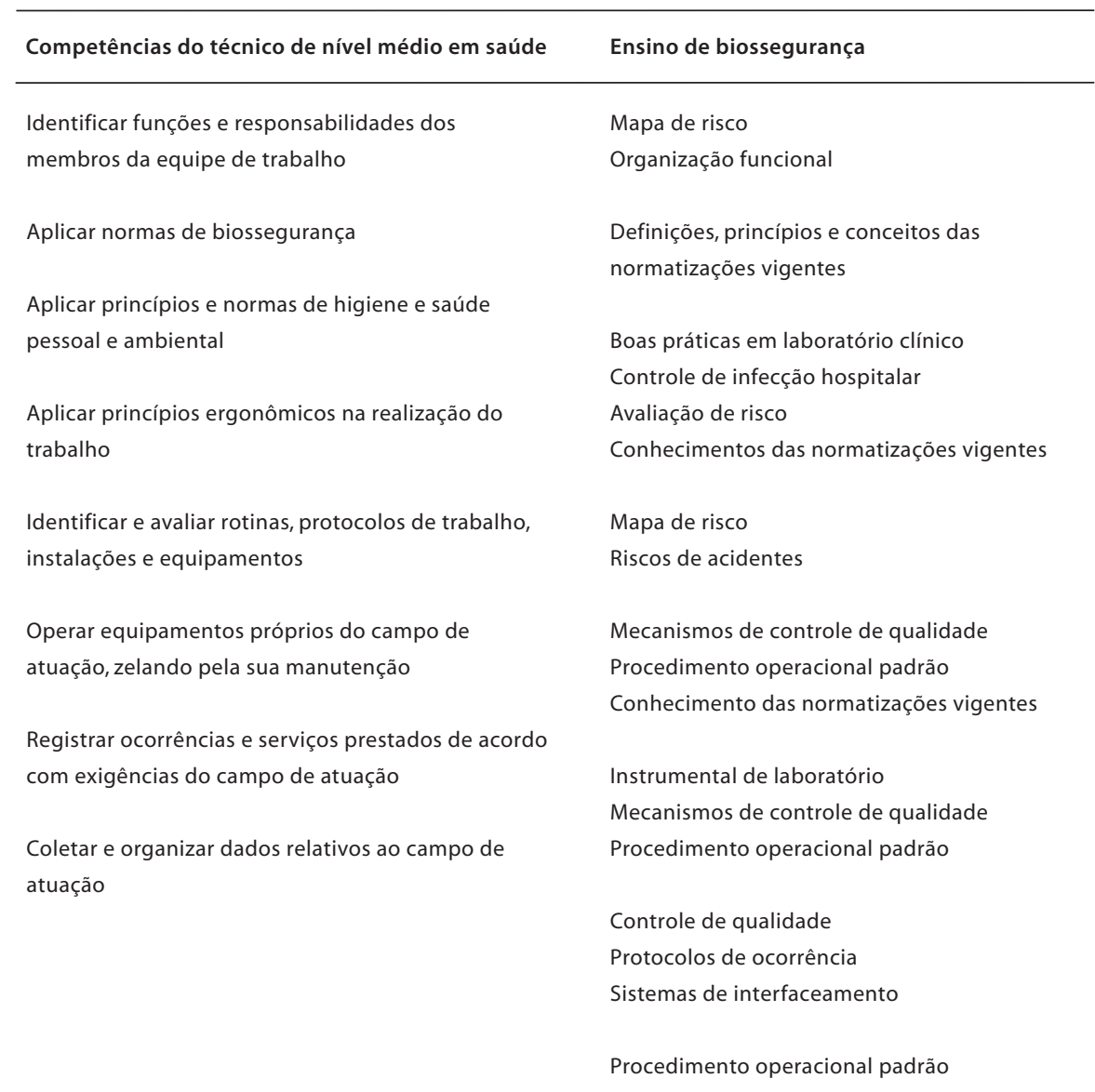

Fonte: Diretrizes curriculares nacionais para a educação profissional de nível técnico na área de saúde (Brasil, 1999).

As unidades escolares consideradas na pesquisa possuem autonomia administrativa estabelecida pela Lei de Diretrizes e Bases da Educação Nacional (lei n. 9.394/96), elaborando os seus projetos político-pedagógicos de maneira a atender o que se encontra preconizado nas diretrizes curriculares, de modo que conteúdos programáticos possam ser abordados com um enfoque interdisciplinar.

A disciplina Biossegurança e Fundamentos do Laboratório Clínico, oferecida nas escolas em que atuam os professores ouvidos nesta pesquisa, 
apresenta uma gama enorme de possibilidades de integração com outras disciplinas. Esse aspecto de integração horizontal é facilitado pelo fato de que, em várias outras disciplinas, diversos aspectos inerentes à disciplina Biossegurança e Fundamentos de Laboratório Clínico podem ser abordados com diferentes enfoques, destacando-se, entre eles, o manuseio de determinados equipamentos, as boas práticas em laboratório clínico, a importância dos equipamentos de proteção individual e coletiva, os níveis de contenção laboratoriais necessários para realizar determinados procedimentos, o que ajuda a minimizar os riscos.

A biossegurança é fundamental para o profissional de análises clínicas, porque, para esse profissional, todas as áreas de trabalho são críticas. Frequentemente o técnico em análises clínicas entra em contato com materiais biológicos em amostras cegas na sua prática cotidiana, de modo que necessita saber como utilizar-se das medidas preventivas e, inclusive, saber como agir em caso de acidente. Saber como trabalhar com segurança para si e para os outros, seja em condições precárias ou em plena conformidade às normas de biossegurança, está relacionado não apenas aos conhecimentos recebidos na escola, mas também (e sobretudo) à formação e experiência que adquire e acumula ao longo da vida profissional e que se manifesta no modo como ele mobiliza recursos cognitivos para agir em uma situação complexa que apresenta riscos.

De acordo com Pereira e Ramos (2006), a realidade dos ambientes de trabalho onde esse profissional será inserido é, muitas vezes, inadequada e deficitária em termos de equipamentos básicos necessários para realizar as atividades. Portanto, a formação deve valorizar o potencial crítico dos técnicos. Como asseveram as autoras:

Formar profissionais da saúde não significa, em nenhum nível, a mera adaptação ao existente, com seus fetiches e formas de alienação. [Ao contrário] trata-se do trabalho paciente de criticar, mediar, construir uma percepção crítica do profissional de nível médio que trabalha nos serviços de saúde. O que implica conhecimentos teóricos e práticos, culturais e técnicos, qualificando o trabalho e o cidadão no contexto do respeito, da remuneração justa, da participação ativa no cotidiano dos serviços de saúde, na visão crítica qualificada em relação ao país e suas contradições (Pereira e Ramos, 2006, p. 52).

Nesse contexto, para formar profissionais na perspectiva da biossegurança, são necessárias atividades com enfoque teórico-prático, a partir do estudo e análise das normatizações vigentes, intercalando atividades práticas com conceitos teóricos, para que o aluno adquira segurança na experimentação. Além disso, os estudos de caso devem ser estimulados, com a discussão pautada em depoimentos de profissionais sobre a realidade de seu campo de atuação, valendo-se de fotografias de ambientes de trabalho, 
situações de acidentes e relatos e discussões sobre como proceder diante de sinistros. Dessa forma, é estimulada a postura crítica do aluno, que adquire e desenvolve um 'saber fazer' teórico-prático, tendo consciência tanto dos riscos inerentes à sua ocupação quanto da sua posição no mercado de trabalho.

O professor, como agente formador, precisa se aperfeiçoar, sempre, por meio de leituras, participação em congressos, reuniões, seminários, debates e através da realização de cursos que contribuam para o seu crescimento intelectual e para o enriquecimento de seu trabalho docente. Sendo, ininterruptamente, um questionador da sua práxis, analisando o que pode ou não ser modificado na sua metodologia de trabalho, o professor se tornará, ele próprio, um crítico de sua postura e de seu desempenho profissional. Como ensina Freire:

É nesse sentido também que [para a leitura crítica da realidade] tanto no caso do processo educativo quanto no do ato político, uma das questões fundamentais seja a clareza em torno de a favor de quem e do quê, portanto contra quem e contra o quê, fazemos a educação e a favor de quem e do quê, portanto contra quem e contra o quê, desenvolvemos a atividade política. Quanto mais ganhamos esta clareza através da prática, tanto mais percebemos a impossibilidade de separar o inseparável: a educação da política. Entendemos então, facilmente, não ser possível pensar, sequer, a educação, sem que se esteja atento à questão do poder (Freire, 1989, p. 15).

Esta pesquisa constitui-se em um estudo de caso realizado em 2008, mediante uma abordagem qualitativa, que teve como objetivo compreender a metodologia de ensino utilizada por docentes da disciplina Biossegurança e Fundamentos do Laboratório Clínico do Curso Técnico em Análises Clínicas, nas duas escolas técnicas da rede pública estadual de ensino que oferecem o curso técnico concomitante ao ensino médio, localizadas na Região Metropolitana do Rio de Janeiro.

A importância de considerar, como sujeitos da investigação, docentes da rede pública de ensino do Rio de Janeiro, que estão formando futuros profissionais para trabalharem no SUS, justifica-se com base nos dados do censo escolar de 2001, que demonstram que o maior mercado de trabalho em saúde e a maior oferta de serviços do setor saúde se encontram na Região Sudeste, com o estado do Rio de Janeiro apresentando a maior quantidade de cursos técnicos de nível médio em saúde.

As informações e os dados para subsidiar o estudo foram obtidos por meio de entrevistas gravadas, orientadas por questionário 5 e posteriormente transcritas para análise do conteúdo das respostas. Entrevistaram-se três professores, tendo como critério de escolha a docência na disciplina Biossegurança e Fundamentos do Laboratório Clínico, correspondendo a 100\% do universo amostral. 
Foram realizadas perguntas referentes aos recursos utilizados, à prática docente, às referências bibliográficas e conteúdos trabalhados pelos docentes, além da caracterização da importância da disciplina para o profissional de análises clínicas. Os temas foram escolhidos de modo a possibilitar a análise da prática pedagógica docente e compreender a metodologia de ensino utilizada.

Os professores foram informados dos objetivos da pesquisa, tomaram ciência de que suas identidades e as escolas seriam preservadas e assinaram Termos de Consentimento Livre e Esclarecido, que permanecem arquivados.

\section{Resultados e discussão}

\section{Perfil dos docentes entrevistados}

Os professores entrevistados apresentam o seguinte perfil: o Professor I (Escola A), com 37 anos de idade, do gênero masculino, possui graduação em Ciências Biológicas há 13 anos, pós-graduação lato sensu em Docência Superior e em Análises Clínicas. O Professor II (Escola A), com 42 anos de idade, do gênero masculino, possui graduação em Ciências Biológicas há 21 anos e pós-graduação stricto sensu em Ciências (Microbiologia e Imunologia). O Professor III (Escola B), com 29 anos de idade, do gênero feminino, possui graduação em Ciências Biológicas há 7 anos, pós-graduação lato sensu em Vigilância Sanitária e em Educação, e pós-graduação stricto sensu em Saúde Pública (subárea Saneamento Ambiental).

Apresentam-se a seguir os resultados e análises com base nas ideias centrais dos discursos concernentes a cada tópico tratado no questionário. A análise do discurso foi realizada com base em estudos de Lefèvre, Lefèvre e Teixeira (2000).

\section{Prática pedagógica}

Na pesquisa foi possível observar que, em um curso de caráter teóricoprático, é mais desejável que os docentes que nele atuam dominem os aspectos práticos da profissão que ensinam, proporcionando um ambiente favorável ao desenvolvimento das habilidades teórico-práticas dos alunos (Quadro 2). Dessa forma, o docente poderá transmitir, com mais segurança a sua vivência prática em laboratório e relacioná-la a aspectos teóricos do conhecimento, ou seja, quanto mais experiência e cursos direcionados na área de análises clínicas o docente possuir, maiores serão as possibilidades de desenvolver um trabalho mais efetivo junto aos alunos.

O estudo permitiu, ademais, perceber ou constatar uma tendência, entre os docentes, de enfatizar, em suas aulas, o estudo dos procedimentos 
e barreiras primárias de contenção como equipamentos de proteção individual e coletiva, boas práticas em laboratório, uso de microscópio e ambientação (Quadro 2). Não foram obtidas respostas que abordassem a temática das barreiras secundárias de contenção, como cabines de segurança biológica ou de segurança química, sinalização ou aspectos de cunho mais gerencial. Esse foco pode indicar a tendência de associar o risco às atitudes do profissional, alimentando a percepção de que esse trabalhador é resignado e culpado pelas falhas que ocorrem no processo de trabalho. Não se busca, então, promover, em sua formação, o desenvolvimento de um espírito crítico capaz de atuar sobre o ambiente de trabalho, modificando-o, melhorando-o e, no caso específico da biossegurança, reduzindo os riscos.

\section{Quadro 2}

Ideias centrais no discurso quanto à prática pedagógica

\begin{tabular}{|c|c|c|}
\hline Professor I & Professor II & Professor III \\
\hline $\begin{array}{l}\text { Prática pedagógica comumente } \\
\text { empregada: aulas teóricas, } \\
\text { dinâmicas em grupo, estudo } \\
\text { dirigido, estudo de caso. }\end{array}$ & $\begin{array}{l}\text { Prática pedagógica comumente } \\
\text { empregada: aulas teóricas (primeiro } \\
\text { momento), dinâmicas em grupo, } \\
\text { estudo de caso, práticas } \\
\text { laboratoriais (segundo momento). }\end{array}$ & $\begin{array}{l}\text { Prática pedagógica comumente empregada: aulas práticas, } \\
\text { teóricas, dinâmicas em grupo, estudo dirigido, estudo de caso. }\end{array}$ \\
\hline $\begin{array}{l}\text { 1ª ideia: não realiza aulas } \\
\text { práticas, diversifica em } \\
\text { dinâmicas na teoria. }\end{array}$ & $\begin{array}{l}1^{\text {a }} \text { ideia: aulas teóricas, aulas } \\
\text { práticas somente em planejamento. }\end{array}$ & $\begin{array}{l}\text { 2a ideia: trabalha a biossegurança na paramentação e no uso } \\
\text { de variados EPI. }\end{array}$ \\
\hline $\begin{array}{l}\text { 2a ideia: análise de situação - } \\
\text { erro, risco, uso inadequado de } \\
\text { equipamentos de proteção }\end{array}$ & $\begin{array}{l}2^{\text {a }} \text { ideia: trabalha na teoria os riscos } \\
\text { e perigos, biológicos e químicos. }\end{array}$ & $\begin{array}{l}\text { 3a ideia: estimula a diferenciação e segregação de resíduos } \\
\text { gerados, estudo da simbologia de cores e confecção de mapa } \\
\text { de risco. }\end{array}$ \\
\hline \multirow[t]{4}{*}{ individual (EPI). } & $\begin{array}{l}\text { 3a ideia: exemplo de aula prática } \\
\text { que pode ser dada: extração de } \\
\text { DNA da cebola, com o objetivo de } \\
\text { ter o primeiro contato, postura, } \\
\text { cobrança. }\end{array}$ & $\begin{array}{l}\text { 4a ideia: apresenta aos alunos, mas não dá muita ênfase aos } \\
\text { aspectos teóricos como as normatizações e procedimentos } \\
\text { operacionais padrão. } \\
\text { 5a ideia: houve uma mudança, trazer a prática para os alunos } \\
\text { desde o primeiro ano, deixando a segurança em primeiro lugar. }\end{array}$ \\
\hline & $\begin{array}{l}\text { 4a ideia: práticas para desinfecção } \\
\text { do banho-maria, fazer atividades no } \\
\text { microscópio, lavagem de mãos. }\end{array}$ & $\begin{array}{l}\text { 6a ideia: trabalha microscopia sem microrganismos, através de } \\
\text { práticas mais seguras com o objetivo de ambientá-los. }\end{array}$ \\
\hline & & $\begin{array}{l}\text { 7a ideia: antes da modificação, os alunos chegavam ao } \\
\text { segundo ano sem conhecimentos práticos, sem saber } \\
\text { manusear o microscópio. }\end{array}$ \\
\hline & & $\begin{array}{l}\text { 8a ideia: pensa em ambientar os alunos, tornar o laboratório } \\
\text { mais comum para eles. }\end{array}$ \\
\hline
\end{tabular}

Fonte: Os autores. 


\section{Recursos didáticos utilizados}

Pode-se presumir que a precariedade dos recursos didáticos nas escolas induz o docente a trabalhar apenas o básico, tendendo a assumir uma postura de acomodação e, eventualmente, usando essa precariedade como subterfúgio para justificar a carência de experiências práticas. O que se observa é certa tendência ao tradicionalismo, contraditória aos Parâmetros Curriculares Nacionais do Ensino Médio e prejudicial à formação do técnico em análises clínicas. Entretanto, não se pode imputar apenas ao professor tal responsabilidade, pois as instâncias educacionais competentes deveriam destinar maiores recursos e equipamentos às unidades de ensino, gerando, dentre outros ganhos, professores motivados e alunos bem formados (Quadro 3).

Quadro 3

\begin{tabular}{|c|c|c|}
\hline Professor I & Professor II & Professor III \\
\hline $\begin{array}{l}\text { Recursos utilizados: quadro, } \\
\text { retroprojetor e apostilas. }\end{array}$ & $\begin{array}{l}\text { Recursos utilizados: quadro, } \\
\text { retroprojetor, apostilas. }\end{array}$ & $\begin{array}{l}\text { Recursos utilizados: quadro e } \\
\text { televisão. }\end{array}$ \\
\hline \multirow[t]{2}{*}{$\begin{array}{l}\text { Ideia: o uso do projetor } \\
\text { multimidia é muito restrito. }\end{array}$} & $\begin{array}{l}1^{\text {a }} \text { ideia: na primeira etapa, } \\
\text { só teoria. }\end{array}$ & $\begin{array}{l}\text { Ideia: a escola tem poucos } \\
\text { recursos. }\end{array}$ \\
\hline & $\begin{array}{l}\text { 2a ideia: parte teórica para } \\
\text { conscientizar da importância } \\
\text { de entrar no laboratório. }\end{array}$ & \\
\hline
\end{tabular}

Fonte: Os autores.

\section{Fontes utilizadas}

Foi observado que as regulamentações em biossegurança 6 - normas regulamentadoras (NR) do Ministério do Trabalho e Emprego (MTE); resoluções da Diretoria Colegiada (RDC) da Agência Nacional de Vigilância Sanitária (Anvisa); e resoluções do Conselho Nacional do Meio Ambiente (Conama) - mesmo sendo da maior importância para o desenvolvimento de competências imprescindíveis ao trabalho do técnico da área da saúde, 
sequer foram mencionadas pelos sujeitos do estudo (Quadro 4). Cabe ressaltar que a regulação é fundamental no ensino de biossegurança, tanto que, no Brasil, o Ministério da Saúde, a Fundação Oswaldo Cruz (Fiocruz), a Anvisa, a Comissão Técnica Nacional de Biossegurança e a Comissão de Biossegurança em Saúde, dentre outros órgãos, trabalham em prol de estabelecer critérios e regulamentar aspectos relacionados à biossegurança. Entretanto, para que ocorram mudanças concretas no campo da saúde, essa temática e seus conteúdos devem estar incluídos em todo o itinerário formativo dos profissionais da saúde.

\section{Quadro 4}

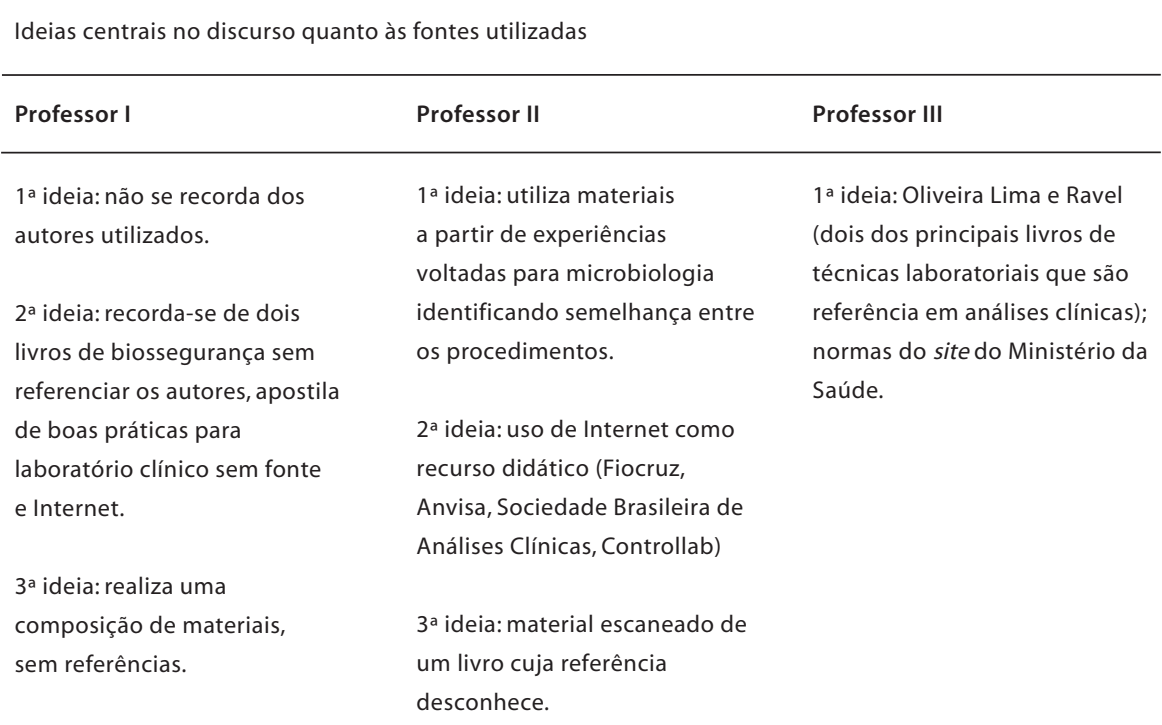

Fonte: Os autores.

\section{Importância da biossegurança na formação}

A visão do professor quanto ao ensino de biossegurança, de acordo com os resultados da pesquisa, está diretamente relacionada com sua formação profissional. O aprofundamento nos estudos (como cursos de pós-graduação lato e stricto sensu) contribui para que o docente adquira mais clareza quanto aos objetivos e metodologias empregadas no ensino da disciplina e influi de maneira positiva no seu desempenho (Quadro 5). 
Resultados obtidos a partir das ideias centrais no discurso quanto à importância da biossegurança na formação

\begin{tabular}{|c|c|c|}
\hline Professor I & Professor II & Professor III \\
\hline $\begin{array}{l}\text { 1a ideia: biossegurança } \\
\text { importante para todas as } \\
\text { disciplinas. }\end{array}$ & $\begin{array}{l}\text { 1a ideia: a disciplina fará com } \\
\text { que os alunos possam ter boas } \\
\text { práticas em laboratório. }\end{array}$ & $\begin{array}{l}\text { 1a ideia: biossegurança é } \\
\text { importante na formação } \\
\text { porque o aluno vai, quando se } \\
\text { formar, trabalhar com fluidos }\end{array}$ \\
\hline $\begin{array}{l}2^{\mathrm{a}} \text { ideia: trabalhar em } \\
\text { laboratório facilita mostrar } \\
\text { algo prático para os alunos. }\end{array}$ & $\begin{array}{l}\text { 2a ideia: trazer sempre que } \\
\text { possível um caso real, como } \\
\text { síndrome respiratória aguda, } \\
\text { e dengue. }\end{array}$ & $\begin{array}{l}\text { corpóreos de outras pessoas, } \\
\text { com material contaminado. } \\
\text { 2a ideia: profissional como }\end{array}$ \\
\hline $\begin{array}{l}\text { 3a ideia: o processo de } \\
\text { aprendizagem deveria ser } \\
\text { continuado, não deveria } \\
\text { ter biossegurança só no } \\
\text { primeiro ano. }\end{array}$ & $\begin{array}{l}3^{a} \text { ideia: importância do recurso } \\
\text { visual por trabalhar com aluno } \\
\text { com deficiência auditiva. }\end{array}$ & $\begin{array}{l}\text { agente contaminador por onde } \\
\text { passa. Sem conhecimento de } \\
\text { biossegurança, o problema é } \\
\text { potencializado. }\end{array}$ \\
\hline
\end{tabular}

Fonte: Os autores.

Os três professores demonstraram nas falas perceber a importância do ensino de biossegurança para o profissional em análises clínicas, mas por razões diferenciadas. Os professores I e III apresentam uma visão mais clara desta importância para o processo de trabalho do profissional que está sendo formado e posteriormente será inserido no SUS. Já o professor II restringese às boas práticas em laboratório clínico, formando um aluno também com a visão restrita quanto à biossegurança e, provavelmente, um profissional que encontrará dificuldades no processo de trabalho no que concerne à sua segurança laboral. Somente o professor I caracteriza a importância do ensino de biossegurança com enfoque interdisciplinar (Quadro 5).

\section{Realidade do mercado}

Os docentes entrevistados demonstraram em seus discursos que a temática biossegurança trabalhada não retrata a realidade do mercado de trabalho, e o professor I é o único que assume tal fato em seu discurso.

Tanto o professor II quanto o professor III possuem visões errôneas da realidade do mercado de trabalho para o técnico em análises clínicas: o professor II associa tal atividade à pesquisa, e o professor III tenta aproximar a realidade do mercado da realidade escolar, mas ainda está distante do que se observa nos laboratórios clínicos. O professor III tem como principal recurso as aulas práticas, fato considerado complicado pelo professor II, que em seu discurso exprime uma dificuldade em realizar tais aulas, o que torna difícil a percepção do aluno no que tange à biossegurança (Quadro 6). 
Quadro 6

Resultados obtidos a partir das ideias centrais no discurso quanto à realidade do mercado

\begin{tabular}{|c|c|c|}
\hline Professor I & Professor II & Professor III \\
\hline $\begin{array}{l}1 \text { a ideia: a escola é um sonho e } \\
\text { o mercado é a realidade. }\end{array}$ & $\begin{array}{l}\text { 1a ideia: tenta trabalhar com os } \\
\text { alunos questões que realmente } \\
\text { acontecem no dia a dia e que }\end{array}$ & $\begin{array}{l}1^{\text {a }} \text { ideia: o trabalho retrata a } \\
\text { realidade do mercado, a partir } \\
\text { de casos que aconteceram. }\end{array}$ \\
\hline 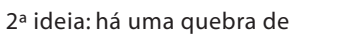 & vão acontecer na prática. & \\
\hline paradigmas. & 2a ideia: é muito complicado & $\begin{array}{l}2^{\mathrm{a}} \text { ideia: experiência prática em } \\
\text { laboratório, buscando sempre }\end{array}$ \\
\hline $\begin{array}{l}3^{3} \text { ideia: o aluno se questiona e } \\
\text { questiona todo mundo, muitos }\end{array}$ & $\begin{array}{l}\text { trabalhar questões do dia a dia } \\
\text { com } 35-40 \text { alunos, tem que }\end{array}$ & alguma coisa nova. \\
\hline $\begin{array}{l}\text { utilizam medidas de } \\
\text { biossegurança, outros acabam }\end{array}$ & dividir a turma. & $\begin{array}{l}\text { 4a ideia: tem a análise clínica } \\
\text { como mercado específico, não }\end{array}$ \\
\hline $\begin{array}{l}\text { se perdendo e reproduzindo } \\
\text { o erro. }\end{array}$ & $\begin{array}{l}\text { 3a ideia: visão de mercado } \\
\text { direcionada para microbiologia } \\
\text { ou pesquisa. }\end{array}$ & enfoca a pesquisa. \\
\hline $\begin{array}{l}4^{\mathrm{a}} \text { ideia: a diferença de } \\
\text { realidades é muito grande. }\end{array}$ & & \\
\hline
\end{tabular}

Fonte: Os autores.

\section{Considerações finais}

Não é fácil a tarefa de identificar as causas e pensar soluções para superar o descompasso observado entre a formação do profissional e as necessidades do mundo do trabalho em saúde, especificamente no que diz respeito à formação para uma prática segura, notadamente pela escassez de estudos específicos relacionados ao tema. O presente artigo enfatiza a necessidade de promover ações concretas no sentido de melhorar a estrutura curricular, as condições dos ambientes de trabalho e a formação dos professores que atuam nos cursos técnicos em análises clínicas, tendo como base e referência a realidade de duas escolas da rede pública do Rio de Janeiro que oferecem essa formação técnica, integrada ao ensino médio.

Os resultados da pesquisa que fundamenta este artigo sugerem a necessidade de reformulações da prática pedagógica desenvolvida pelos professores, possibilitando a formação do profissional técnico em análises clínicas em consonância com as reais necessidades do SUS. Também se constatou que o professor deve estimular a visão crítica de seus alunos numa perspectiva emancipatória, centrada no desenvolvimento da aprendizagem para a vida, sensibilizando-o e aguçando-o para que tenha uma postura profissional compatível com a sua importância para o serviço de saúde, além de incentivá-lo para a sua atualização teórica e prática. 
O estudo aponta para a importância do tema biossegurança não ter seu enfoque restrito à biologia, devendo abranger, também, o ambiente de trabalho dos profissionais de saúde, sem deixar de contemplar os profissionais de nível médio e básico. Muitos assuntos como formação profissional do técnico em análises clínicas, regulamentação do trabalho, relações de classe entre técnico de nível médio e profissionais de nível superior em saúde, visão do profissional técnico, entre outros, podem e necessitam ser pesquisados.

Por fim, mas não menos importante, mencione-se que as práticas médicas a cada dia requerem maior participação dos profissionais vinculados ao apoio diagnóstico. Dessa forma o técnico em análises clínicas deixa de ser o mero expectador da assistência e assume papel fundamental na tríade paciente-médico-cura. Nesse contexto, somente uma formação crítica adequada à realidade do mundo do trabalho pode fazer com que o profissional se sinta apto e seguro para exercer a profissão, de modo a minimizar as chances de exposição aos riscos inerentes às suas atividades sem comprometer a sua saúde e a de todos que convivem com ele.

\section{Agradecimentos}

Às unidades de formação em análises clínicas e aos professores que permitiram a realização das entrevistas e contribuíram para a realização da pesquisa.

\section{Notas}

1 Técnica de Laboratório do Ministério da Saúde do Hospital Federal de Bonsucesso, Rio de Janeiro, Brasil. Mestre em Saúde Pública pela Escola Nacional de Saúde Pública Sergio Arouca, Fundação Oswaldo Cruz (Ensp/Fiocruz). <andrezzapiccoli@yahoo.com.br> Correspondência: Departamento de Saneamento e Saúde Ambiental, Escola Nacional de Saúde Pública Sergio Arouca, Fundação Oswaldo Cruz, Rua Leopoldo Bulhões, 1.480, sala 520, Manguinhos, CEP 21041-210, Rio de Janeiro, RJ, Brasil.

2 Pesquisadora da Escola Nacional de Saúde Pública Sergio Arouca, Fundação Oswaldo Cruz (Ensp/Fiocruz), Rio de Janeiro, RJ, Brasil. Doutora em Saúde Pública pela Ensp/Fiocruz. $<$ monicaw@ensp.fiocruz.br $>$

3 Pesquisador da Escola Nacional de Saúde Pública Sergio Arouca, Fundação Oswaldo Cruz (Ensp/Fiocruz), Rio de Janeiro, RJ, Brasil. Doutor em Educação pela Universidade Federal do Rio de Janeiro (UFRJ).<amancio@ensp.fiocruz.br> 
4 Entende-se por risco ocupacional os fatores existentes no processo de trabalho com origem em seus componentes e na forma de organização do trabalho capazes de gerar acidentes, doenças e outros agravos à saúde do trabalhador (Mastroeni, 2004).

5 Questionário semiestruturado, abordando as seguintes questões: 1. Formação docente: graduação, pós-graduação, capacitação/atualização, outros (instituição e ano de formação). 2. Metodologia de ensino: a) Recursos (quadro, retroprojetor, TV, projetor de slides, projetor multimídia, outros); b) Prática (aulas teóricas, dinâmicas em grupo, práticas laboratoriais, estudo de caso). Descrever como ocorre o processo escolhido; 3. Quais as fontes que utiliza para as aulas? 4. Por que acha importante para o aluno ter aulas de biossegurança? 5. Os conteúdos de biossegurança trabalhados retratam a realidade do mercado de trabalho?

6 Dentre as normas regulamentadoras do MTE, a NR 5 estabelece a criação da Comissão Interna de Prevenção de Acidentes e critérios para elaboração do mapa de risco, a NR 6 estabelece os critérios e parâmetros para o uso de equipamentos de proteção individual, a NR 9 estabelece o programa de prevenção de riscos ambientais no ambiente de trabalho, a NR 26 estabelece a sinalização de segurança a ser usada nos locais de trabalho para prevenção de acidentes, e a NR 32 estabelece diretrizes para a implementação de medidas de segurança e saúde no trabalho em serviços de saúde. Dentre as resoluções da Diretoria Colegiada da Anvisa, a RDC n. 50/02 regulamenta o planejamento, programação, elaboração e avaliação de projetos físicos de estabelecimentos assistenciais de saúde, e a RDC n. 306/04 dispõe sobre o manejo dos resíduos de serviços de saúde juntamente com a resolução n. 358/05 do Conama.

\section{Referências}

ALMEIDA, Ana Beatriz de Sá; ALBUQUERQUE, Marli Brito Moreira de. Biossegurança: um enfoque histórico através da história oral. História das Ciências de Saúde - Manguinhos, Rio de Janeiro, v. 7, n. 1, p. 171$183,2000$.

AMÂNCIO FILHO, Antenor. Cenários e situações da formação em saúde no Brasil. Boletim Técnico do Senac, Rio de Janeiro, v. 23, n. 3, p. 11-25. 1997.

BAHIA, Ligia. A démarche do privado e público no sistema de atenção à saúde no Brasil em tempos de democracia e ajuste fiscal, 1988-2008. In: MATTA, Gustavo Corrêa; LIMA, Júlio César França (Orgs.). Estado, sociedade e formação profissional em saúde: contradições e desafios em 20 anos de SUS. Rio de Janeiro: Ed. Fiocruz; Escola Politécnica de Saúde Joaquim Venâncio, 2008. p. 123-185.

BRASIL. Ministério da Educação. Conselho Nacional de Educação. Câmara de Educação Básica. Resolução CEB n. 4, de 8 de dezembro de 1999. Institui as Diretrizes Curriculares Nacionais para a Educação Profissional de Nível Técnico. Diário Oficial da União, Brasília, DF, 22 de dez. 1999, Seção 1, pág. 229.

Lei de Diretrizes e Bases da Educação Nacional. Lei n. 9.394, de 20 de dezembro de 1996. Disponível em: <http://portal. mec.gov.br/arquivos/pdf/ldb.pdf $>$. Acesso em: 13 jun. 2008. 
. Ministério da Educação. Instituto Nacional de Estudos e Pesquisas Educacionais. Censo Escolar 2001. Brasília: Inep, 2002.

Ministério do Trabalho. Norma Regulamentadora n. 5. Disponível em: $<$ www.mte.gov.br/legislacao/normas_ regulamentadoras/nr_05.asp >. Acesso em: 8 ago. 2010.

Ministério do Trabalho. Norma Regulamentadora n. 6. Disponível em: $<$ www.mte.gov.br/legislacao/normas_ regulamentadoras/nr_06.pdf $>$. Acesso em: 8 ago. 2010.

Ministério do Trabalho. Norma Regulamentadora n. 9. Disponível em: <www.mte.gov.br/legislacao/normas_ regulamentadoras/nr_09_at.pdf $>$. Acesso em: 8 ago. 2010.

Ministério do Trabalho. Norma Regulamentadora n. 26. Disponível em: $<$ www.mte.gov.br/legislacao/normas_ regulamentadoras/nr_26.pdf $>$. Acesso em: 8 ago. 2010.

Ministério do Trabalho. Norma Regulamentadora n. 32. Disponível em: $<$ www.mte.gov.br/legislacao/normas_ regulamentadoras/nr_32.pdf $>$. Acesso em: 8 ago. 2010.

Ministério da Saúde. Agência Nacional de Vigilância Sanitária. Resolução da Diretoria Colegiada n. 50 de fevereiro de 2002. Regulamento técnico para planejamento, programação, elaboração e avaliação de projetos físicos de estabelecimentos assistenciais de saúde. Disponível em: <www. anvisa.gov.br/legis/resol/2002/50_02rdc.pdf>. Acesso em: 28 mai. 2012.

Ministério da Saúde. Agência Nacional de Vigilância Sanitária. Resolução da Diretoria Colegiada n. 306 de 7 de dezembro de 2004. Dispõe sobre o Regulamento Técnico para o gerenciamento de resíduos de serviços de saúde. Diário Oficial da União, Brasília, DF, 10 dez., Seção 1, 2004.
Ministério do Meio Ambiente. Conselho Nacional de Meio Ambiente. Resolução n. 358 de 29 de abril de 2005. Dispõe sobre o tratamento e a disposição final dos resíduos dos serviços de saúde e dá outras providências. Disponível em: <www.mma. gov.br/port/conama/res/res05/res35805.pdf>. Acesso em: 28 mai. 2012.

FREIRE, Paulo. A importância do ato de ler: em três artigos que se completam. São Paulo: Autores Associados; Cortez. 1989.

FRIGOTTO, Gaudêncio. Política de formação continuada do servidor público: uma alternativa metodológica à doutrina neoliberal. In: OFICINA CONCEITUAL 'CONSTRUINDO A GESTÃO PÚBLICA', 1. 2011. Disponível em: <www.fdrh.rs.gov.br/upload/1306773213 ARTIGO_FRIGOTTO.pdf $>$. Acesso em: 28 mai. 2012 .

LEFÈVRE, Fernando; LEFÈVRE, Ana Maria Cavalcanti; TEIXEIRA, Jorge Juarez Vieira. O discurso do sujeito coletivo: uma nova abordagem metodológica em pesquisa qualitativa. Caxias do Sul: Ed. Universidade de Caxias do Sul (Educs), 2000.

LESSA, Sérgio. Trabalho e sujeito revolucionário: a classe operária. In: MATTA, Gustavo Corrêa; LIMA, Júlio César França (Orgs.). Estado, sociedade e formação profissional em saúde: contradições e desafios em 20 anos de SUS. Rio de Janeiro: Ed. Fiocruz; Escola Politécnica de Saúde Joaquim Venâncio, 2008. p. 249-311.

MASTROENI, Fábio Marco. Biossegurança aplicada a laboratórios e serviços de saúde. São Paulo: Atheneu. 2004.

PEREIRA, Isabel Brasil. A educação dos trabalhadores da saúde sob a égide da produtividade. In: MATTA, Gustavo Corrêa; LIMA, Júlio César França (Orgs.). Estado, sociedade e formação profissional em saúde: contradições e desafios em 20 anos de SUS. Rio de Janeiro: Ed. Fiocruz; Escola Politécnica de Saúde Joaquim Venâncio, 2008. p. 393-420. 
PEREIRA, Isabel Brasil; RAMOS, Marise Nogueira. Educação profissional em saúde. Rio de Janeiro: Ed. Fiocruz. 2006.

RAPPARINI, Cristiane. Riscos biológicos e vigilância ocupacional. In: SIMPÓSIO SOBRE RISCO E PREVENÇÃO DE ACIDENTES COM PERFUROCORTANTES, 1., 2001. CD-ROM.

RIBEIRO, Polyana da Costa; RIBEIRO, Ana Cláudia da Costa; LIMA JÚNIOR, Francisco de Paula Barroso. Perfil dos acidentes de trabalho em um hospital de Teresina, PI. Cogitare Enfermagem, Paraná, v. 15, n. 1, p. 110-116, 2010.

SADER, Eder. Reforma do Estado, seguridade social e saúde no Brasil. In: MATTA, Gustavo Corrêa; LIMA, Júlio César França (Orgs.). Estado, sociedade e formação profissional em saúde: contradições e desafios em 20 anos de SUS. Rio de Janeiro: Ed. Fiocruz; Escola Politécnica de Saúde Joaquim Venâncio, 2008. p. 35-87.
SANTOS, Boaventura de Souza. A globalização e as ciências sociais. Linha do Horizonte. São Paulo: Cortez, p. 25-102, 2005.

SOUSA, Marcia de. Conhecimento e aplicação das precauções universais pelos elementos da equipe de enfermagem de um hospital governamental. Dissertação (Mestrado em Enfermagem) - São Paulo, Departamento de Enfermagem, Universidade Federal de São Paulo, 1994.

TEIXEIRA, Pedro; VALLE, Silvio (Orgs.). Biossegurança: uma abordagem multidisciplinar. Rio de Janeiro: Ed. Fiocruz, 1996.

WERMELINGER, Mônica; MACHADO, Maria Helena; AMÂNCIO FILHO, Antenor. Técnicos em saúde: constituição de uma identidade. Divulgação em Saúde para Debate, Rio de Janeiro, n. 45, p. 89-104, 2010.

Recebido em 03/02/2011

Aprovado em 27/02/2012 